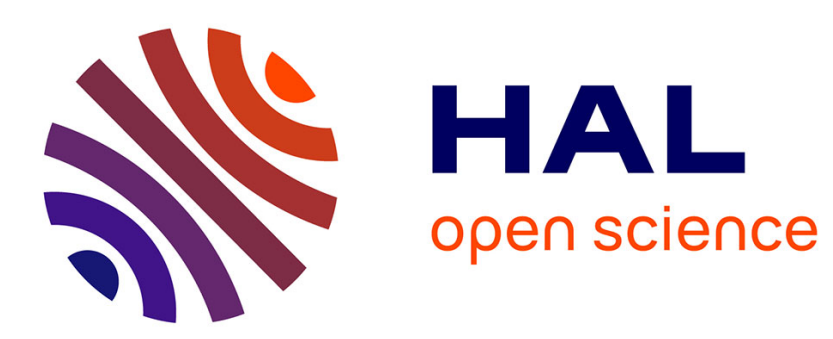

\title{
The oxidation mechanism of Pt20Ni30Al50
}

\author{
P. van Manen, G. Leibbrandt, R. Klumpes, J. de Wit
}

\section{To cite this version:}

P. van Manen, G. Leibbrandt, R. Klumpes, J. de Wit. The oxidation mechanism of Pt20Ni30Al50. Journal de Physique IV Proceedings, 1993, 03 (C9), pp.C9-123-C9-131. 10.1051/jp4:1993910 . jpa00252341

\section{HAL Id: jpa-00252341 https://hal.science/jpa-00252341}

Submitted on 1 Jan 1993

HAL is a multi-disciplinary open access archive for the deposit and dissemination of scientific research documents, whether they are published or not. The documents may come from teaching and research institutions in France or abroad, or from public or private research centers.
L'archive ouverte pluridisciplinaire HAL, est destinée au dépôt et à la diffusion de documents scientifiques de niveau recherche, publiés ou non, émanant des établissements d'enseignement et de recherche français ou étrangers, des laboratoires publics ou privés. 


\title{
The oxidation mechanism of $\mathrm{Pt}_{20} \mathrm{Ni}_{30} \mathrm{Al}_{50}$
}

P.A. van Manen $\left({ }^{1}\right)$, G.W.R. Leibbrandt $\left({ }^{2}\right)$, R. Klumpes $\left({ }^{1}\right)$ and J.H.W. $\operatorname{de~Wit}\left({ }^{1}\right)$

(1) Delft University of Technology, Laboratory for Materials Science, Div. Corrosion Technology and Electrochemistry, Rotterdamseweg 137, 2628AL, Dleft, the Netherlands

$\left(^{2}\right)$ University of Utrecht, Department of Atomic and Interface Physics, P.O. Box 80 000, 3508 TA, Utrecht, the Netherlands

\begin{abstract}
Additions of platinum to aluminium oxide forming alloys are known to imporve their high temperature corrosion resistance. This is known as the "precious metal effect". In this study the effect of platinum on the oxidation mechanism was investigated by comparing the oxidation mechanism of $\beta-\mathrm{NiAl}$ and $\mathrm{Pt}_{20} \mathrm{Ni}_{30} \mathrm{Al}_{50}$. This composition agrees with the average composition of a platinum modified aluminide coating. The alloys were oxidized at temperatures from 1000 to $1200^{\circ} \mathrm{C}$. The growth of the oxide scale on the NiAl alloy proceeds both by aluminium and by oxygen diffusion through the scale resulting in growth within the scale. However, on $\mathrm{Pt}_{20} \mathrm{Ni}_{30} \mathrm{Al}_{50}$ the growth of the scale is limited to the oxide/gas interface due to a predominant aluminium transport through the scale. Therefore the growth stresses are reduced. Another difference is the extensive void formation at the $\beta$-NiAl/oxide interface. This was not observed on the $\mathrm{Pt}_{20} \mathrm{Ni}_{30} \mathrm{Al}_{50}$ samples. The phenomena mentioned above are the two likely reasons for the improved oxide scale adherence.
\end{abstract}

\section{Introduction.}

The adherence of aluminium oxide scales on coating alloys can be imporved by the addition of platinum. This has resulted in the development of several platinum modified aluminide coatings [1]. The most common structures in the coating are $\mathrm{PtAl}_{2}, \mathrm{PtAl}$ and NiAl. Little is known about the precious metal effect. A few models have been proposed for the imporved oxidation resistance $[2,3,4]$. In this study the oxidation mechanism and the adherence of the oxide scale of $\mathrm{Pt}_{20} \mathrm{Ni}_{30} \mathrm{Al}_{50}$ (further designated as $\mathrm{PtNiAl}$ ) and of $\beta-\mathrm{NiAl}$ are compared.

\section{Experimental.}

$\beta$-NiAl and PtNiAl alloys were made by arc melting specpure nickel and aluminium rods with the appropriate amount of platinum (wire, $99.99 \%$ ). Oxidation experiments were carried out at temperatures between 900 and $1200^{\circ} \mathrm{C}$ in pure oxygen. Before oxidizing the samples were ground and polished down to $1 \mu \mathrm{m}$ diamond paste.

The composition and structure of the alloys were investigated with XRD and EPMA. The morphology of the oxide scale was studied with SEM. TG-experiments were carried out in the Dupont 9900 TG-system $\left(900^{\circ} \mathrm{C}\right.$ ) and a Stanton-Redcroft TG 770 balance system (higher temperatures). RBS and EPMA were used to analyse the oxide scale and the alloy/oxide interface region. (AES is not very suitable because of the presence of the heavy alloying element 
platinum.) The transport properties of the oxide scales were investigated using double oxidation experiments. The double oxidation experiments in ${ }^{18} \mathrm{O}$ followed by ${ }^{16} \mathrm{O}$ and vice versa were performed at 900 and $1070{ }^{\circ} \mathrm{C}$. The ${ }^{18} \mathrm{O}$ in the scale was profiled by making use of Nuclear Reaction Analysis (NRA). The specific nuclear reaction is ${ }^{18} \mathrm{O}(\mathrm{p}, \alpha)^{15} \mathrm{~N}[5]$. With a proton energy of $790 \mathrm{keV}$ and a detection angle of $150^{\circ}$, the $\alpha$-particles from the surface will be detected with an energy of about $3.4 \mathrm{MeV}$. Passing through the oxide scale the primary protons and the $\alpha$-particles loose energy. The $(\mathrm{p}, \alpha)$ reaction cross-section remains virtually constant down an energy of $790 \mathrm{keV}$, and as a result the $\alpha$-energy spectra can readily be interpreted as ${ }^{18} \mathrm{O}$ distribution profiles down to a depth of at least $1 \mu \mathrm{m}$. The depth from which an $\alpha$-particle emerges can be calculated from the energy loss in aluminimoxide. The energy loss in the aluminium-oxide was estimated by taking the weighted average of the tabulated values of the energy losses in aluminium and oxygen [6].

\section{Results.}

The EPMA line scans of the alloys revealed that the PtNiAl and the NiAl samples were homogeneous. The NiAl buttons all had a nickel content of ca. 48 at\%. The composition in at.\% of all the PtNiAl buttons is: $19 \% \mathrm{Pt}, 29 \% \mathrm{Ni}$ and $52 \% \mathrm{Al}$. The NiAl alloys had the $\beta$ $\mathrm{NiAl}$ structure (B2-ordered intermetallic) while the $\mathrm{PtNiAl}$ alloys showed the $\mathrm{CaF}_{2}\left(\mathrm{PtAl}_{2}\right)$ structure (JCPDS card nr. 3-1006 [7]).

The development of the structure of the oxide scale formed on the PtNiAl alloys was similar to that of the scale on $\beta$-NiAl. First a scale is formed of transition oxide(s) of which only $\theta-\mathrm{Al}_{2} \mathrm{O}_{3}$ could be positively identified by XRD. These transition oxide(s) eventually transform to $\alpha-\mathrm{Al}_{2} \mathrm{O}_{3}$. The rate of the transformation of these oxides to $\alpha-\mathrm{Al}_{2} \mathrm{O}_{3}$ is temperature dependent and appeared to be not significantly different from the transformation rate of the oxide scales on $\beta$-NiAl. After 50 hours at $1200^{\circ} \mathrm{C}$, a scale of $\alpha-\mathrm{Al}_{2} \mathrm{O}_{3}$ had formed on the alloy. The $\mathrm{PtNiAl}$ samples showed very little or no spalling during isothermal oxidation compared to the $\mathrm{NiAl}$ alloy which showed heavy spallation at high temperatures.

The samples oxidized at $1000^{\circ} \mathrm{C}$ show a needle and blade structure on top of a compact scale (Fig. 1). Smoothing of this structure has been observed for oxidation periods of 50 hours. The scale morphologies were similar to those observed for the scale on $\beta$-NiAl, only the smoothing of the needle and blade structure was more extensive (Fig. 2). In contrast to the $\beta-\mathrm{NiAl}$ alloy, no voids were observed at the alloy/oxide interface on PtNiAl.

At $1100^{\circ} \mathrm{C}$ the needle and blade structure is much less pronounced. The oxide scale on $\mathrm{PtNiAl}$ shows relatively flat stress and the development of ridges. Also at this temperature no voids were observed. Under the oxide scale on a $\beta$-NiAl substrate large voids can be found.

The scale formed at $1200^{\circ} \mathrm{C}$ consists of relatively flat areas with small globular protrusions separated by ridges (Fig. 3). The oxide scale on $\beta$-NiAl has the same morphology but again there are more ridges (Fig. 4). The so-called "lacey structure" can easily be recognized in these micrographs. After extended oxidation periods the ridges grow until the surface of the scale is completely covered, leaving a smooth scale with ondulations.

The RBS experiments were performed on samples oxidized for 5 minutes and 60 minutes at $900^{\circ} \mathrm{C}$. With this technique, no platinum or nickel could be detected in the ocide scale. This implies that the platinum concentration in the oxide is below $10^{15} \mathrm{at.cm}^{-2}$. The RBS spectra did not show evidence for the presence of an enrichment in platinum or nickel, or a depletion of aluminium at the oxide/alloy interface.

EPMA line scans perpendicular to the alloy/oxide interface did not show any significant deviations in the alloying elements for samples oxidized for 10 hours at $1000^{\circ} \mathrm{C}$. 


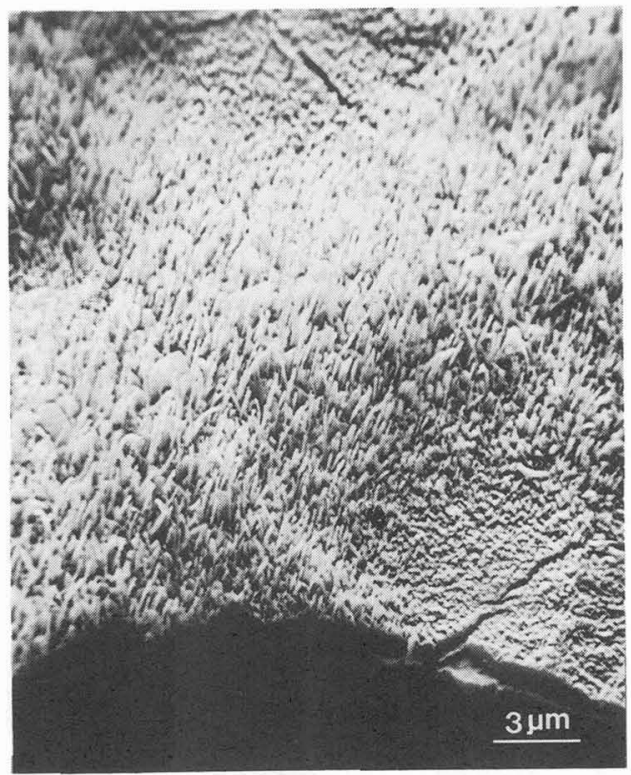

Fig. 1. - SEM micrograph of the oxide scale formed on PtNiAl at $1000^{\circ} \mathrm{C}$ after 20 hours.

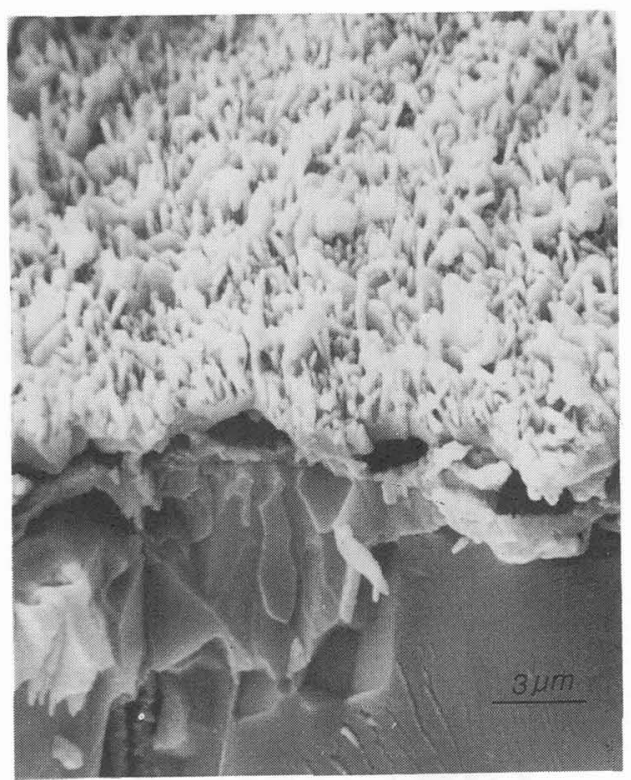

Fig. 2. - SEM micrograph of the oxide scale formed on $\mathrm{NiAl}$ at $1000^{\circ} \mathrm{C}$ after 50 hours. 


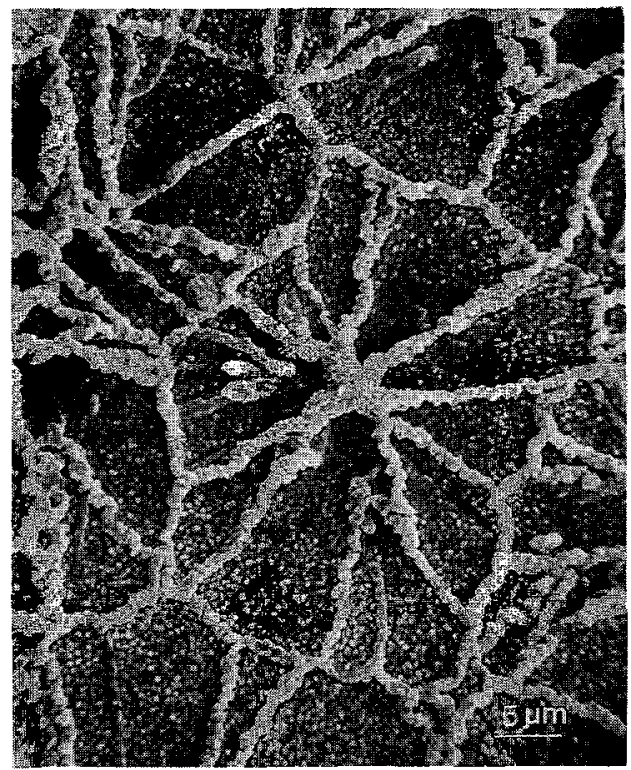

Fig. 3. - SEM micrograph of the oxide scale formed on $\mathrm{PtNiAl}$ at $1200^{\circ} \mathrm{C}$ after 2 hours.

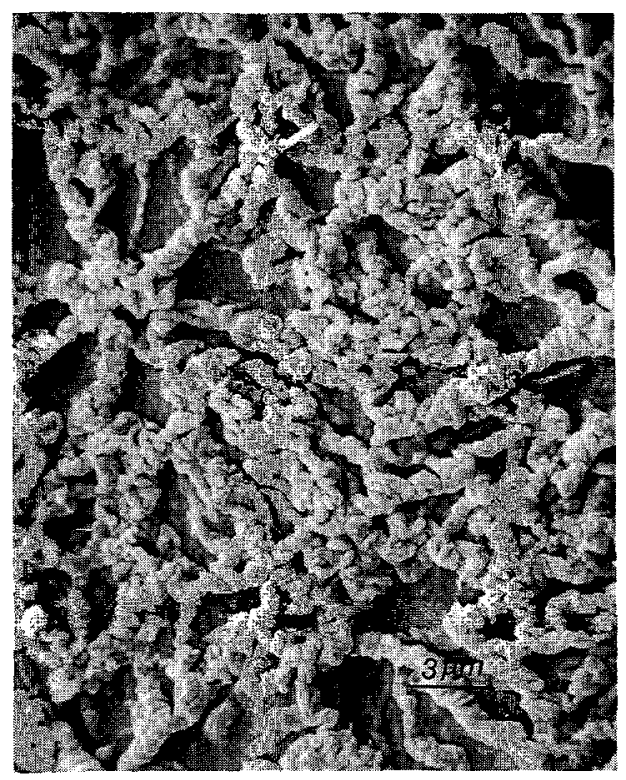

Fig. 4. - SEM micrograph of the oxide scale formed on $\mathrm{NiAl}$ at $1200^{\circ} \mathrm{C}$ after 2 hours. 


\section{Kinetics of the oxidation.}

The weight gain of both PtNiAl samples at $900{ }^{\circ} \mathrm{C}$ (see Fig. 5a) was higher than that of the $\mathrm{NiAl}$ samples. At $1000^{\circ} \mathrm{C}$ the oxidation of the PtNiAl alloy proceeds slower than the oxidation of $\mathrm{NiAl}$ (Fig. 5b). This also holds for the oxidation at $1100^{\circ} \mathrm{C}$ where the differences in the weight gain are even much larger.

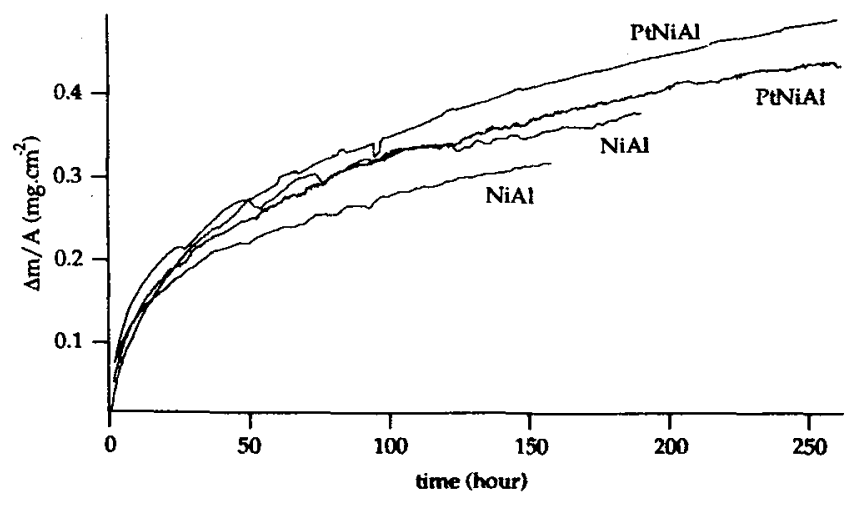

a)

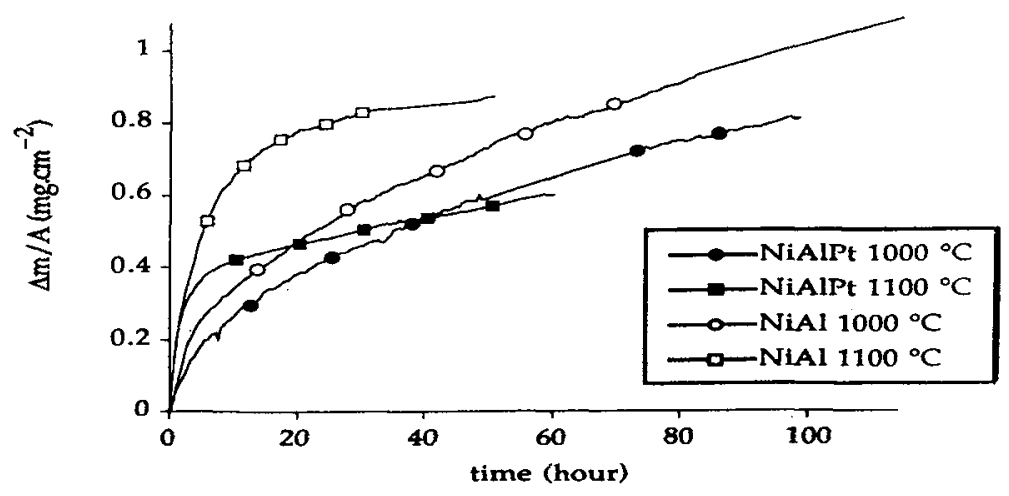

b)

Fig. 5. - TGA curves of $\mathrm{PtNiAl}$ and $\mathrm{NiAl}$ at different temperatures.

\section{Growth mechanism of the scale.}

The growth mechanism of the scale is investigated with NRA. The yield of the $\alpha$-particles can be interpreted as ${ }^{18} \mathrm{O}$-distribution profiles, for the energy range of the $\alpha$-particles is much higher than the energy of the backscattered protons which due to pile up are detected with up to twice the energy of the scattered protons. 
For both $\mathrm{NiAl}$ and NiAlPt the integrated yield of the samples first oxidized in ${ }^{18} \mathrm{O}$ is much higher than thise oxidized first in ${ }^{16} \mathrm{O}$. In view of the oxidation in the two different isotopes the integrated yield of the samples was expected to be greater for the samples oxidized first in ${ }^{16} \mathrm{O}$ and then in ${ }^{18} \mathrm{O}$. In all spectra the integrated yield of the samples first oxidized in ${ }^{18} \mathrm{O}$ was higher, indicating non parabolic growth in this stage. The oxide scale thickness for the $\mathrm{NiAl}$ and PtNiAl alloys is comparable. The NRA-spectra are given in figure 6 .

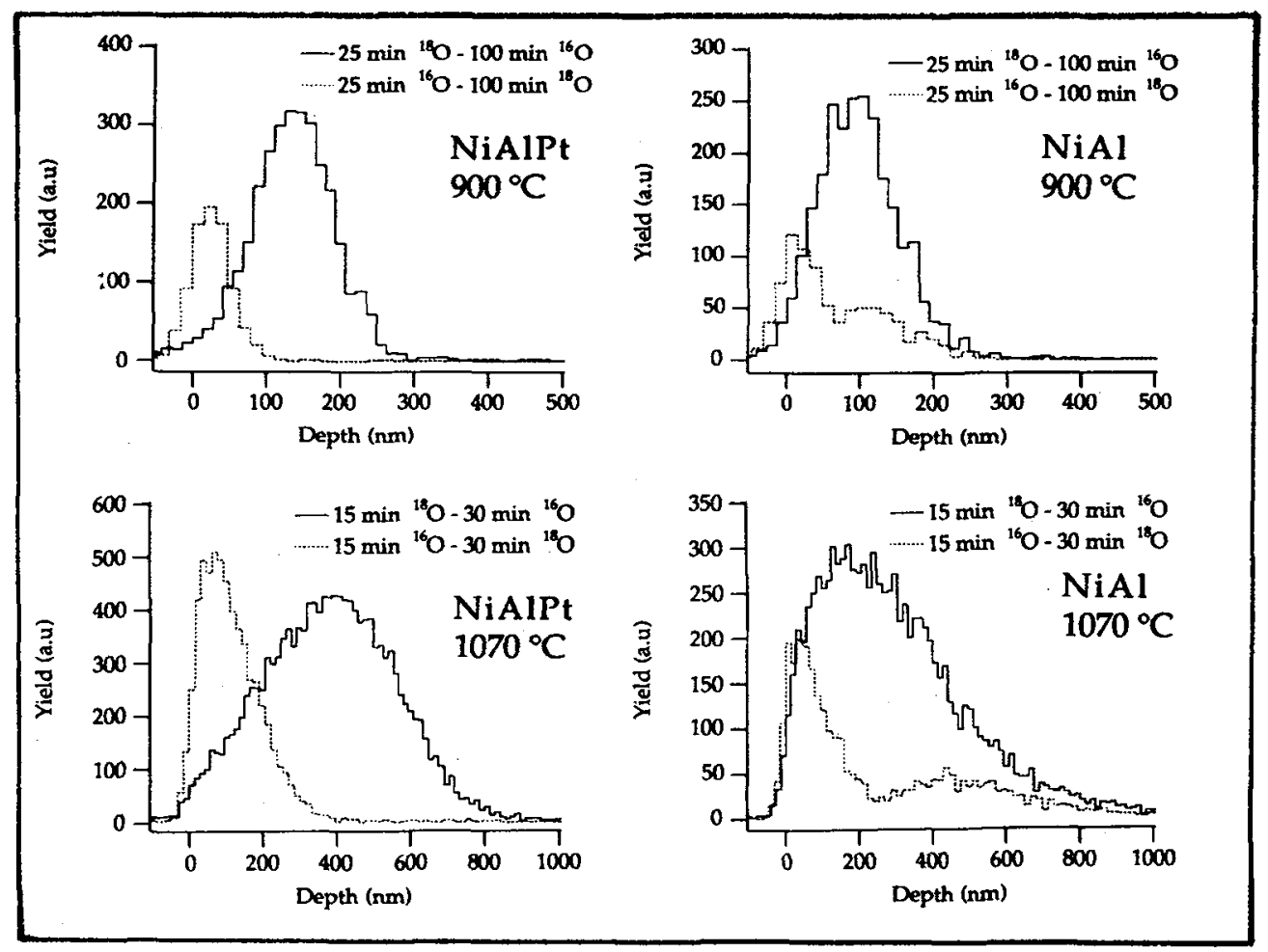

Fig. 6. - NRA $\alpha$-spectra.

- $900{ }^{\circ} \mathrm{C}$ : From the NRA spectrum of NiAl oxidized first in ${ }^{16} \mathrm{O}$ and then in ${ }^{18} \mathrm{O}$, it was found that, ${ }^{18} \mathrm{O}$ was located at the oxide/gas interface while also a large part had penetrated the scale. It can therefore be concluded that the scale grows by oxygen as well as aluminium transport. For the sample oxidized first in ${ }^{18} \mathrm{O}$ only one broad peak was found. If exclusively aluminium or oxygen transport would occur this peak would have been shifted towards one of the interfaces. The spectra of the oxidized PtNiAl are muxh different, and obviously the result of almost exclusive growth by aluminium transport. Oxidation in ${ }^{18} \mathrm{O}$ first, results in a high ${ }^{18} \mathrm{O}$ concentration at the alloy/oxide interface while the ${ }^{18} \mathrm{O}$ remains at the oxide/gas interface after oxidation in ${ }^{16} \mathrm{O}$ first.

- $1070^{\circ} \mathrm{C}$ : The spectrum of the sample first oxidized in ${ }^{18} \mathrm{O}$ shows an ${ }^{18} \mathrm{O}$-distribution with a maximum concentration at a depth of about $200 \mathrm{~nm}$ which relatively slowly decreases towards 
the alloy/oxide interface, indicating that ${ }^{16} \mathrm{O}$ passes through the already present oxide scale which then grows mainly by oxygen and some aluminium transport. The oxide scale on the PtNiAl sample apparently is growing mainly by aluminium transport. The spectrum of the sample oxidized in ${ }^{16} \mathrm{O}$ first shows a ${ }^{18} \mathrm{O}$ distribution with a maximum concentration at the oxide/gas interface.

\section{Discussion.}

The EPMA results show that the alloys were homogeneous. The structure of the NiAl alloys was, as expected, the $\mathrm{CsCl}$ structure. The $\mathrm{PtNiAl}$ alloy was shown to have the $\mathrm{PiAl}_{2}$ structure $\left(\mathrm{CaF}_{2}\right)$.

From the SEM observations it is clear that both alloys oxidize externally, forming an aluminium oxide scale. No internal oxidation or formation of oxide protrusions has been observed.

The oxide scale on the PtNiAl alloy does not contain a detectable amount of platinum in contrast to the results of Cocking et al. [9] who reported large bands of Pt-rich oxide in the scale. Their results were obtained on a platinum modified NiAl coating. If the coating is not homogeneous then internal oxidation is possible leaving platinum in the oxide scale.

The morphology of the oxide scale on PtNiAl is not different from that on NiAl. Both scales formed at low temperatures consist of a neddle like structure on top of a compact scale. Increasing the temperature yields an initially flat scale with ridges that grow out until they cover the scale surface and form a compact flat scale again.

The alloy shows no detectable depletion of aluminium, which can be detected with EPMA, at the alloy/oxide interface. From the RBS results that do not show a marked decrease after the initial step it also shows no high platinum or nickel concentrations.

Table I. - The parabolic rate constants for NiAl and NiAlPt in two stages of the oxidation (at $900{ }^{\circ} \mathrm{C}$ the values given for $k_{p}$ are the average of the two experiments).

\begin{tabular}{|c|c|c|c|}
\hline \multirow[b]{2}{*}{ T $\left({ }^{\circ} \mathrm{C}\right)$} & \multirow[b]{2}{*}{ time interval (min) } & PtNiAl & NiAl \\
\hline & & $10^{-3} \mathrm{kp}$ & 4. hour ${ }^{-1}$ ) \\
\hline 900 & $100-200$ & 2.067 & 1.659 \\
\hline 900 & $5000-7000$ & 0.5268 & 0.756 \\
\hline 1000 & $100-300$ & 13.56 & 8.16 \\
\hline 1000 & $4000-5000$ & 10.2 & 5.286 \\
\hline 1100 & $100-200$ & 40.8 & 51 \\
\hline 1100 & $2000-3000$ & 3.0 & 3.6 \\
\hline
\end{tabular}

The weight gain curves presented in figure 5 show that for the PtNiAl and $\beta$-NiAl the oxidation does not proceed according to a simple parabolic rate law. The total weight gain of both samples oxidized at $1100^{\circ} \mathrm{C}$ is smaller than that for the samples of the same alloys oxidized at $1000^{\circ} \mathrm{C}$. Since on $\mathrm{NiAl}$ and PtNiAl an aluminium oxide scale is formed which 
does not contain a large amount of nickel or platinum, the kinetics of the oxidation were expected to be similar. Nevertheless, as indicated by the $k_{\mathrm{p}}$ values given in table I, large differences exist in the oxidation kinetics for the two alloys. The effect ofthe procedures used in this study can also explain the differences in the total weight gain between the $\mathrm{NiAl}$ and the PtNiAl alloy at $1100^{\circ} \mathrm{C}$, assuming that an aluminium oxide scale is formed more rapidly on the platinum containing alloy. This effect has been reported by Felten and Pettit [8]. The weight gain curves, recorded with the Stanton-Redcroft balance at 1000 and $1100^{\circ} \mathrm{C}$, should not be regarded as very reliable since the experiments were performed with very small samples, suspended on platinum wires which showed a large evaporation weight decrease.

Assuming a constant evaporation rate of the wires the wires the wieght gains were corrected. Dur to the small size of the samples the effects of the edges, that tend to oxidize faster, can not be ignored.

From the results of the NRA experiments it can be concluded that a clear difference between the scale growth mechanism on $\mathrm{NiAl}$ and PtNiAl exists at least in the early stages of the oxidation. On PtNiAl the oxide scale grows predominantly at the oxide/gas interfaces while the scale on NiAl grows within the scale as a result of both oxygen and aluminium transport. Both experiments are performed in the initial oxidation period, in which on both alloys the scale consists primarily of $\theta-\mathrm{Al}_{2} \mathrm{O}_{3}$. The morphology of the oxide scales indicates that after the transition to $\alpha-\mathrm{Al}_{2} \mathrm{O}_{3}$ both scales grow, at least partially, by inward diffusion of oxygen. The effect of platinum on the growth of the scale is therefore most obvious in the initial stage.

Fountain et al. [10] noticed a different oxidation mechanism when platinum (or $\mathrm{PtO}_{2}$ ) was deposited and incorporated in the oxide scale on the sample while it was oxidized. One of the few possibilities through which this platinum addiion can affect the oxidation mechanism is a blosking of transport paths in the oxide scale. From the NRA results it would follow that platinum hinders the diffusion of oxygen through the oxide scale. This is also indirectly suggested by Tatlock and Hurd [11]. The models proposed for the formation of voids at the alloy/oxide interface on the $\mathrm{NiAl}$ are based on the Kirkendall effect and vacancy injection from the oxide in case of outward growing oxides. The growth of the aluminium oxide scale on $\mathrm{NiAl}$, at low temperatures and short oxidation periods, proceeds predominantly by outward diffusion of aluminium through the oxide scale as shown with the NRA experiments. In this initial period the voids are formed at the alloy/oxide interface. After extended oxidation periods with incresing temperatures the voids tend to disappear due to a change in the growth mechanism of the oxide scale involving an increase in the transport of oxygen through the oxide scale. Although, the NRA results clearly show that the oxide scale on PtNiAl grows on the oxide/gas interface, no voids are formed on this alloy. This indicates that just vacancy injection from the oxide scale can not explain the formation of voids. The difference between the diffusion coefficients of nickel and aluminium in NiAl, resulting in a Kirkebdall effect poses an explanation that agrees with these results although the problem associated with this model have not yet been completely resolved. It is, however, possible that the vacancy saturation concentration of the $\mathrm{PtNiAl}$ alloy is much higher than that of the NiAl alloys. In this case the formation of voids would also be suppressed.

\section{Conclusions.}

The presence of large amounts of platinum in NiAl alloys changes the oxidation mechanism. This effect is most prominent in the stage of the formation of the gransition oxides growing by outward diffusion. During the growth of this scale voids are produced at the alloy/oxide interface of $\mathrm{NiAl}$ alloys. On the PtNiAl alloy these voids do not form. Combined with the 
change in transport properties, resulting in lower growth stresses in the scale on the PtNiAl alloy this will have a positive effect on the oxide scale adherence [12]. Although the TGexperiments show that the growth rate in the initial stage is smaller and the duration of the initial stage seems to be shorter for the PtNiAl alloys, no conclusions are based on these experiments since this effect has not yet been reproduced.

\section{Acknowledgements.}

The authors wish to thank N. van der Pers for performing the XRD measurements and W.G. Sloof and E.J.A. van Dam for SEM and EPMA.

\section{References}

[1] SChaefFer J., Kim G.M., MEIER G.H., PetTUT F.S., The role of active elements in the oxidation of high temperature alloys, E. Lang Ed. (Elsevier, London, 1989) p.231.

[2] Wing R.G., McGill I.R., Platinum Met. Rev. 25 (1981) 94.

[3] FELTEN E.J., Oxid. Met. 10 (1976) 23.

[4] JACKSON M.R., RIARDEN J.R., Metal. Trans. A8 (1977) 1697.

[5] Christensen N.S., Jensen F., StensGaARd I., Nucl. Instrum. Methods B51 (1990) 97.

[6] ANDERSEN H.H., ZIEGLER J.F., Hydrogen stopping powers and ranges in all elements (Pergamon, New York, 1977).

[7] JCPDS powder difraction files (A.S.T.M., Philadelphia, 1969).

[8] Felten E.J., PeTtit, Oxid. Met. 10 (1976) 189.

[9] Cocking J.L., Johnston G.R., Richards P.G., Platinum Met. Rev. 29 (1) (1985).

[10] Fountain J.G., Golightly F.A., Stott F.H., Wood G.C., Oxid. Met. 10 (1976) 341.

[11] Tatlock G.J., Hurd T.J., Oxid. Met. 22 (1984) 201.

[12] STOTT F.H., The role of active elements in the oxidation of high temperature alloys, E. Lang Ed. (Elsevier, London, 1989) p.3. 